\title{
Advantages of legislation for advance directives in Hong Kong and areas of concern for clinicians
}

CY Tse *, FHKAM (Medicine), FRCP

Honorary Advisor, Hong Kong Society of Palliative Medicine, Hong Kong

*Corresponding author: tse_cy@hotmail.com

Hong Kong Med J 2021;27:309-11

https://doi.org/10.12809/hkmj208985

\section{Legislative proposal}

After a public consultation from September to December of 2019, ${ }^{1}$ the Government of Hong Kong published a consultation report on legislative proposals for advance directives (AD) and dying in place in July 2020, ${ }^{2}$ aiming to finalise a draft bill for introduction in the next Legislative Council term. In the proposed legislation, a valid and applicable AD has the same effect as a contemporaneous refusal of treatment by a person with mental capacity, and overrides treatment decisions based on best interests. A non-statutory model AD form will be used, on which a mentally competent adult can refuse life-sustaining treatments (including artificial nutrition and hydration) in pre-specified end-stage conditions. There will not be a central registry. To facilitate an $\mathrm{AD}$ being followed in emergencies outside the hospital setting, a statutory prescribed Do-Not-Attempt Cardiopulmonary Resuscitation (DNACPR) form will be used, on which the doctor certifies that the $\mathrm{AD}$ is valid and applicable and recommends no CPR. The DNACPR form can also be used for minors and incompetent adults without an $\mathrm{AD}$ and having advanced irreversible illnesses, if there is consensus that CPR is not in the best interests of the patient.

\section{Advantages of legislation}

This is an important milestone in the development of end-of-life care in Hong Kong.

Firstly, legal uncertainties and legal obstacles can be clarified. The Government will make specific provisions in the Mental Health Ordinance such that a valid and applicable AD shall prevail, and a registered doctor or an appointed guardian cannot, based on the best interests principle, override a valid AD. The Fire Services Ordinance provisions in respect of the duty to resuscitate will be changed, enabling DNACPR forms to be accepted and enforced.

Secondly, there will be legal protection for treatment providers. A treatment provider will not incur any civil or criminal liability for providing treatment if he/she reasonably believes that a valid and applicable AD does not exist, or for withholding or withdrawing treatment if he/she reasonably believes that a valid and applicable AD exists. The same protection applies to DNACPR forms. Medical professionals will also be exempted from disciplinary proceedings for professional misconduct for a decision made in good faith and with reasonable care.

Thirdly, with confidence provided by the legislation and with public education that goes with the process, there will be better acceptance of $\mathrm{AD}$ among treatment providers, patients, family members, and the public.

\section{Special areas of concern for clinicians}

However, there are areas of concern that clinicians and professional organisations should take note.

\section{Assessing validity and applicability of advance directives}

Before respecting an $\mathrm{AD}$, a clinician has to decide whether the $\mathrm{AD}$ is valid and applicable. Legislation for $\mathrm{AD}$ does not relieve a clinician from this responsibility. On validity, under normal circumstances, the clinician should see the original copy of the $\mathrm{AD}$, and note that the AD is sufficiently clear, has not been withdrawn and is not being challenged. In special situations, if the person has done something that clearly goes against the AD which suggests that he/she has changed his/her mind, the AD is not valid. An example is a Jehovah's Witness with an AD refusing blood transfusion who was recently noted to attend Buddhist gatherings.

On applicability, an $\mathrm{AD}$ is applicable only when the person has the pre-specified conditions in the $\mathrm{AD}$ form and is no longer mentally capable of making healthcare decisions. It will not be applicable if there are reasonable grounds for believing that the current circumstances were not anticipated by the patient and, if they had been anticipated by him/her, would have affected his/her decision. An example is a disseminated malignancy patient with an AD refusing intubation and $C P R$, now requiring surgery under general anaesthesia for an acute reversible illness.

This prudent approach, adapted from the practice in England and Wales, ${ }^{3}$ gives priority to 
saving life if there is doubt whether the refusal of treatment is really what the patient intended in the particular circumstance. However, a burden is put on the clinician in difficult situations. ${ }^{4}$ Though the legislation will provide protection for the clinician if the decision is made in good faith and with reasonable care, it is important for clinicians to understand the complexities and nuances in such decisions, especially when the AD is not made on a model form. It will be useful for our professional organisations to prepare reminders or case illustrations for the purpose.

\section{Legal requirements for witnesses of advance directives}

Under the common law framework, for an AD to be legally binding, the patient should have been "offered sufficient, accurate information to make an informed decision." ${ }^{5}$ Recently, the pendulum has swung, and some overseas legislations do not require patients to receive any information about the treatment they are refusing in the AD. ${ }^{6}$ The proposed legislation in Hong Kong adopts a more balanced approach: "the medical practitioner (as a witness) should be satisfied that the person has the capability to make an $\mathrm{AD}$ and has been informed of the nature and effect of the directive and the consequences of refusing the treatments specified in the AD." To address this legal requirement, which is different from informed consent, relevant professional organisations should develop guidelines to assist clinicians to understand their role.

\section{Promoting advance directives in patients with serious illnesses}

Promoting $\mathrm{AD}$ in patients with serious illnesses, clinicians have to understand the limitations of an AD. ${ }^{7}$ Advance decisions refusing treatment may not be adequate or appropriate to cover all scenarios in end-of-life decision making. In-the-moment decisions are important. ${ }^{8}$ Therefore, discussion on AD should be made through an advance care planning (ACP) process, ${ }^{9}$ which is more than just for signing an AD. Through ACP, the patient can express values, wishes and preferences for medical and personal care. Although these values and preferences are not legally binding, they can assist clinicians and family members to make appropriate in-the-moment decisions in the best interests of the patient. Through ACP, the patient and family can also be better prepared emotionally for future crises. ${ }^{10}$ The patient can also appoint a proxy decision maker if necessary, when the law on continuing powers of attorney is passed in Hong Kong. ${ }^{11}$

\section{Witnessing advance directives for healthy persons}

With the AD legislation, clinicians may be approached by healthy persons to witness an AD. Clinicians need to note that it is debatable whether it is appropriate for healthy persons to make an $\mathrm{AD}$ other than for permanent severe neurological damage. ${ }^{12}$ Firstly, many types of diseases can progress to a terminal stage, and one needs a vast amount of complex medical information before a meaningful directive can be made. Secondly, a person's acceptance of symptoms or disability may change with his/her bodily condition. ${ }^{13}$ However, discussing with the family about one's values, wishes and treatment preferences regarding the dying process is helpful in general.

\section{Way forward}

Hong Kong ranked lower than Taiwan and Singapore in the 2015 Quality of Death Index. ${ }^{14}$ A lack of legislation for $\mathrm{AD}$ is a possible underlying factor for this. Though the Government's legislative proposal is a welcome initiative, it needs to be accompanied by professional training and guidelines, as well as public education. ${ }^{15}$ We must also look beyond signing ADs. Improvement in palliative care and end-of-life care in Hong Kong will need a multi-pronged approach and concerted effort from all relevant parties. ${ }^{16,17}$

\section{Author contributions}

The author contributed to the concept and design of the study, acquisition and analysis of the data, drafting of the manuscript, and critical revision of the manuscript for important intellectual content. The author had full access to the data, contributed to the study, approved the final version for publication, and takes responsibility for its accuracy and integrity.

\section{Conflicts of interest}

The author has disclosed no conflicts of interest.

\section{Declaration}

The main part of the paper was presented at the virtual MultiSpecialty Medical Mega Conference in Hong Kong on 13 September 2020.

\section{Funding/support}

This study received no specific grant from any funding agency in the public, commercial, or not-for-profit sectors.

\section{References}

1. Food and Health Bureau, Hong Kong SAR Government. End-of-life care: legislative proposals on advance directives and dying in place-consultation document. 2019. Available from: https://www.gov.hk/en/residents/ government/publication/consultation/docs/2019/End-oflife.pdf. Accessed 3 Aug 2020.

2. Food and Health Bureau, Hong Kong SAR Government. End-of-life care: moving forward: legislative proposals on advance directives and dying in place-consultation report. 2020. Available from: https://www.fhb.gov.hk/ download/press_and_publications/consultation/190900_ 
eolcare/e_EOL_consultation_report.pdf. Accessed 3 Aug 2020.

3. Department for Constitutional Affairs, UK Government. Mental Capacity Act 2005 Code of Practice. London: The Stationery Office; 2007.

4. Randall F, Downie RS. End of Life Choices: Consensus and Controversy. Oxford: Oxford University Press; 2010.

5. British Medical Association Medical Ethics Committee. Withholding and Withdrawing Life-prolonging Medical Treatment: Guidance for Decision Making. 3rd ed. Oxford: Blackwell Publishing; 2007.

6. Queensland University of Technology. End of Life Law in Australia. Victoria-key legislation. Available from: https://end-of-life.qut.edu.au/advance-care-directives/ state-and-territory-laws/victoria\#547684. Accessed 3 Aug 2020.

7. Fagerlin A, Schneider CE. Enough: the failure of the living will. Hastings Cent Rep 2004;34:30-42.

8. Sudore RL, Fried TR. Redefining the "planning" in advance care planning: preparing for end-of-life decision making. Ann Intern Med 2010;153:256-61.

9. Hospital Authority of Hong Kong. HA guidelines on advance care planning. Available from: https://www. ha.org.hk/haho/ho/psrm/EACPGuidelines.pdf. Accessed 3 Aug 2020.

10. Thomas K, Lobo B, Detering K, editors. Advance Care
Planning in End of Life Care. 2nd ed. Oxford: Oxford University Press; 2018.

11. Department of Justice, Hong Kong SAR Government. Consultation paper on the continuing powers of attorney bill. 2017. Available from: https://www.doj.gov.hk/eng/ public/pdf/2017/cpa_consulte.pdf. Accessed 3 Aug 2020.

12. Tse CY. Reflections on the development of advance directives in Hong Kong. Asian Bioeth Rev 2016;8:211-23.

13. Fried TR, Byers AL, Gallo WT, et al. Prospective study of health status preferences and changes in preferences over time in older adults. Arch Intern Med 2006;166:890-5.

14. The Economist Intelligence Unit. The 2015 Quality of Death Index: Ranking palliative care across the world. Available from: https://eiuperspectives.economist.com/ sites/default/files/2015\%20EIU\%20Quality\%20of\%20 Death\%20Index\%20Oct\%2029\%20FINAL.pdf. Accessed 3 Aug 2020.

15. Chu WL. One step forward for advance directives in Hong Kong. Hong Kong Med J 2012;18:176-7.

16. Chan KS. Two decades of palliative care. Hong Kong Med J 2002;8:465-6.

17. Morrissey MB, Lang M, Newman B. A Public Health Strategy for Living, Aging and Dying in Solidarity: Designing Elder-centered and Palliative Systems of Care, Environments, Services and Supports. Boca Raton: Taylor and Francis; 2018.

\section{Answers to CME Programme Hong Kong Medical Journal June 2021 issue}

Hong Kong Med J 2021;27:177-83

\section{Expanded carrier screening using next-generation sequencing of 123 Hong Kong} Chinese families: a pilot study
A
1. False
2. False
3. True
4. True
5. False
B
1. True
2. False
3. True
4. True
5. True

Hong Kong Med J 2021;27:184-91

II. Effects of pill splitting training on drug physiochemical properties, compliance, and clinical outcomes in the elderly population: a randomised trial
A
1. False
2. False
3. True
4. True
5. False
B
1. False
2. True
3. False
4. False
5. True 